EXTENDED REPORT

\title{
Photodynamic therapy with PhotoPoint photosensitiser MV6401, indium chloride methyl pyropheophorbide, achieves selective closure of rat corneal neovascularisation and rabbit choriocapillaris
}

\author{
T A Ciulla, M H Criswell, W J Snyder, W Small IV
}

Br J Ophthalmol 2005;89:113-119. doi: 10.1136/bjo.2004.043075

See end of article for authors' affiliations

Correspondence to: Thomas A Ciulla, MD, Macula-RetinaVitreous Section, Midwest Eye Institute, 201 Pennsylvania Parkway, Indianapolis, IN 46280, USA; thomasciulla@ yahoo.com

Accepted for publication 2 June 2004

\begin{abstract}
Aim: The new photosensitiser PhotoPoint MV6401, indium chloride methyl pyropheophorbide, was assessed as a possible ocular photodynamic therapy agent in a rat model of experimentally induced corneal neovascularisation and in choriocapillaris closure in the rabbit. Optimal drug and light activation parameters were determined.

Methods: MV6401 (Miravant Pharmaceuticals, Inc, Santa Barbara, CA, USA) was activated at $664 \mathrm{~nm}$ using a DD3-0665 (Miravant Systems Inc) 0.5 W diode laser. Corneal neovascularisation in rats was induced using an $\mathrm{N}$-heptanol technique. The evaluated drug dosages, light dosages, and post-injection activation times ranged from $0.01-0.1 \mu \mathrm{mol} / \mathrm{kg}, 5-25 \mathrm{~J} / \mathrm{cm}^{2}$, and $10-60$ minutes, respectively. The efficacy of MV6401 on normal choriocapillaris and choroidal vessels was evaluated in rabbits with indirect ophthalmoscopy, fundus photography, fluorescein angiography, and histology. In rabbits, the evaluated drug dosages, light dosages, and post-injection activation times ranged from 0.025$0.25 \mu \mathrm{mol} / \mathrm{kg}, 3.3-20 \mathrm{~J} / \mathrm{cm}^{2}$, and 10 minutes, respectively.

Results: In the rat corneal neovascularisation model, an optimal intravenous drug dosage of $0.075 \mu \mathrm{mol} /$ $\mathrm{kg}$ was activated by a $20 \mathrm{~J} / \mathrm{cm}^{2}$ light dose at 10 minutes after drug administration, the results of which demonstrated early evidence of efficacy in ocular neovascularisation. In rabbits, closure of the normal choriocapillaris was selectively achieved at a drug dosage of $0.15 \mu \mathrm{mol} / \mathrm{kg}$ using light doses from 3.3 to $20 \mathrm{~J} / \mathrm{cm}^{2}$.

Conclusion: PhotoPoint MV6401 is a potent photosensitiser that demonstrates both efficacy and selectivity in experimental ocular models.
\end{abstract}

\section{MATERIALS AND METHODS}

\section{Photosensitiser}

MV6401 (supplied by Miravant Medical Technologies, Santa Barbara, CA, USA) was formulated in egg yolk phosphati- dylcholine (EYP) (purity $>98 \%$ ). The concentration of the ready to use formulation was approximately $1 \mathrm{mM}$. The agent was stored at $2-8^{\circ} \mathrm{C}$ until used. The vials were wrapped in aluminium foil to avoid light exposure at all times. The photosensitiser was administered intravenously before light treatment.

\section{Laser}

A low power (0.5 W) diode laser (Model DD3-0665; Miravant Systems, Inc, Santa Barbara, CA, USA) at $664 \mathrm{~nm}$ was coupled into a slit lamp adapter on a Haag Streit slit lamp to deliver the laser light following MV6401 administration.

\section{Rat corneal neovascularisation model}

Animals

Fifty five male Sprague Dawley rats weighing 0.30-0.45 kg were used in accordance with the resolutions on research animal use developed by the Association for Research in Vision and Ophthalmology as well as the guidelines developed by the Miravant Medical Technologies institutional animal care and use committee.

The corneal neovascularisation was induced using an $\mathrm{N}$ heptanol (99\%) corneal scrub technique. The drug and light dose ranged from $0.01-0.1 \mu \mathrm{mol} / \mathrm{kg}$ (lateral tail vein injection) and $5-25 \mathrm{~J} / \mathrm{cm}^{2}$, respectively. Animals were

Abbreviations: AMD, age related macular degeneration; CNVM, choroidal neovascular membranes; EYP, egg yolk phosphatidylcholine; PDT, photodynamic therapy; PIAT, post-injection activation time; RPE, retinal pigment epithelium 


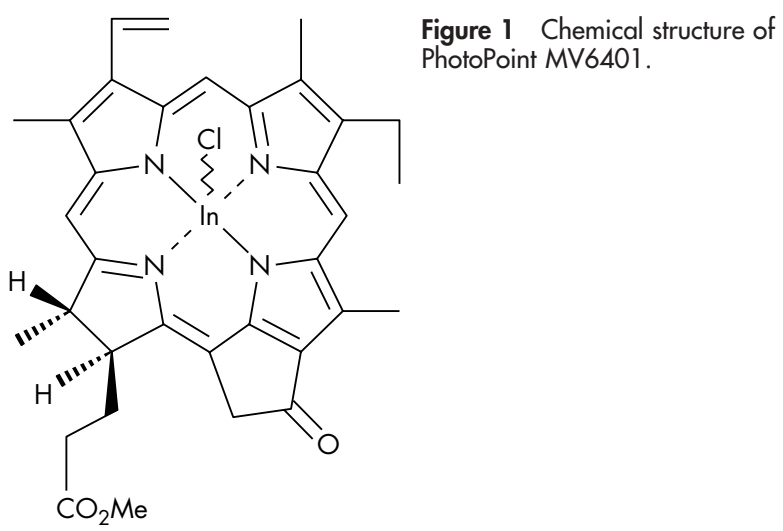

anaesthetised with ketamine hydrochloride $(50.0 \mathrm{mg} / \mathrm{kg})$ and acepromazine $(0.5 \mathrm{mg} / \mathrm{kg})$ before inducing corneal neovessels, laser PDT treatment, and fluorescein angiography.

\section{Induction of corneal neovascularisation}

Corneal neovascularisation was induced by N-heptanol chemical injury, a technique used previously. ${ }^{90}$ In brief, Nheptanol was applied to the corneal epithelium, including the limbal epithelium and accompanying stem cells. The animals were monitored daily and antibiotics were administered to avoid infection (antibiotic topical ointment with or without $2.27 \%$ enrofloxacin antibacterial injectable solution). Three to 4 weeks after $\mathrm{N}$-heptanol application, corneal neovessels formed a uniform network across the entire cornea and were ready for PDT treatment.

\section{Illumination parameters}

A $3 \mathrm{~mm}$ diameter spot of laser light $\left(664 \mathrm{~nm} ; 150 \mathrm{~mW} / \mathrm{cm}^{2}\right)$ was delivered directly to the cornea without a contact lens. PDT treatment was applied to both eyes at light doses ranging from $5-25 \mathrm{~J} / \mathrm{cm}^{2}$. Light treatment began 10-60 minutes following MV6401 administration.

\section{Clinical evaluation}

Corneal fluorescein angiography was performed at baseline and up to 7 or 28 days following PDT to evaluate the neovessel closure. Approximately $0.3 \mathrm{ml}$ sodium fluorescein $(10 \%)$ was administered intravenously at the time of angiography.

\section{Histology}

A group of nine Sprague Dawley rats was treated with MV6401 PDT and killed at 1, 7, or 28 days following PDT for histological evaluation. The animals received an intravenous dose of MV6401 at $0.075 \mu \mathrm{mol} / \mathrm{kg}$ and light treatment 10 minutes later with $20 \mathrm{~J} / \mathrm{cm}^{2}$. Immediately following euthanasia, the eyes were enucleated and submerged in
$10 \%$ buffered formalin. The cornea was dissected and embedded in glycol methacrylate, sectioned, and stained with haematoxylin and eosin.

\section{Group assignments}

The study was divided into several phases to elucidate the optimal PDT parameters in the corneal neovascularisation model. The first phase evaluated the drug and light doseresponse while the time interval between drug injection and laser light treatment remained constant. The second phase maintained a constant drug dose, while the laser light dose and time interval between photosensitiser injection and laser light treatment were varied. The third phase followed the PDT treatment up to 28 days post-treatment to evaluate lesion evolution; histological analysis was carried out at selected time points in addition to corneal fluorescein angiography.

\section{Drug and light dose response}

MV6401 was intravenously administered to 19 animals at $0.01-0.10 \mu \mathrm{mol} / \mathrm{kg} 10$ minutes before light treatment and the light dose was varied from 5 to $25 \mathrm{~J} / \mathrm{cm}^{2}$ (see table 1). Both eyes were treated at different light doses. Fluorescein angiography was performed at baseline, 1 day, and 7 days post-PDT in this phase of the study.

\section{Post-injection activation time responses}

In this phase of the study the post-injection activation time (PIAT) interval between MV6401 injection and laser light application was increased; specified times up to 60 minutes were investigated (see table 2). MV6401 was intravenously administered to 17 animals at a fixed dosage of $0.05 \mu \mathrm{mol} / \mathrm{kg}$ and PDT treatment was applied at light dosages of 5-25 $\mathrm{J} / \mathrm{cm}^{2}$. Fluorescein angiography was performed at baseline, 1 day, and 7 days following PDT.

\section{Post-treatment evaluations}

Evaluation of ongoing changes in corneal tissues following MV6401 PDT was monitored in 19 animals for periods up to 28 days; eyes from nine of these 19 animals underwent histological processing and analysis at 1,7 , or 28 days postPDT (see table 3 ). The animals were intravenously administered 0.075 or $0.10 \mu \mathrm{mol} / \mathrm{kg}$ of MV6401 and PDT treated 10 minutes later with light dosages that ranged from 15$25 \mathrm{~J} / \mathrm{cm}^{2}$. Fluorescein angiography was performed at baseline, 1, 7, 14, 21, and 28 days following PDT for the first group of animals. The histology group of animals underwent fluorescein angiography at baseline, 1, 7, and 28 days.

\section{Rabbit choriocapillaris model \\ Animals}

Twenty four female Dutch Belted rabbits weighing 1.5-3.0 kg were used in accordance with the resolutions on research animal use developed by the Association for Research in Vision and Ophthalmology as well as the guidelines

Table 1 Rat drug and light dosage regimen for the dose-response study in experimentally induced corneal neovascularisation (time interval $=10$ minutes)

\begin{tabular}{llll}
\hline $\begin{array}{l}\text { MV6401 dose } \\
(\mu \mathrm{mol} / \mathbf{k g})\end{array}$ & $\begin{array}{l}\text { No* per } \\
\text { MV6401 dose }\end{array}$ & $\begin{array}{l}\text { Light dose } \\
\left(\mathrm{J} / \mathrm{cm}^{2}\right)\end{array}$ & $\begin{array}{l}\text { Not per drug/light } \\
\text { combination }\end{array}$ \\
\hline 0.01 & 3 & $15,20,25$ & 2 \\
0.025 & 2 & 20,25 & 2 \\
0.05 & 5 & $5,10,15,20,25$ & 2 \\
0.075 & 5 & $5,10,15,20,25$ & 2 \\
0.10 & 4 & $5,10,15,20$ & 2 \\
\hline
\end{tabular}

*Number of animals.

†Number of eyes. 


\begin{tabular}{|llll|}
\hline \multicolumn{2}{l}{ Table 2} & Rat post-injection activation time (PIAT) and light dosage regimen \\
\hline $\begin{array}{l}\text { Time interval } \\
\text { (minutes) }\end{array}$ & $\begin{array}{l}\text { No* per } \\
\text { time interval }\end{array}$ & $\begin{array}{l}\text { Light dosage } \\
\left(\mathrm{J} / \mathrm{cm}^{2}\right)\end{array}$ & $\begin{array}{l}\text { Not per PIAT/light } \\
\text { combination }\end{array}$ \\
\hline 20 & 5 & $5,10,15,20,25$ & 2 \\
30 & 6 & $5,10,15$ & 2 \\
& 20,25 & 3 \\
60 & 6 & $5,10,15$ & 2 \\
& 20,25 & 3 \\
\hline *Number of animals. & & \\
tNumber of eyes. \\
(Animals were intravenously administered $0.05 \mu \mathrm{mol} / \mathrm{kg}$ of MV6401.) \\
\hline
\end{tabular}

developed by the Indiana University institutional animal care and use committee. Rabbits received intravenous injections ranging from $0.025-0.25 \mu \mathrm{mol} / \mathrm{kg}$ of MV6401 via marginal ear vein. Following photosensitiser injection, animals were housed in subdued lighting conditions before and after treatment to minimise potential photosensitivity reactions. Control animals were injected with EYP alone using a volume equivalent to $1.0 \mu \mathrm{mol} / \mathrm{kg}$ formulated MV6401. All rabbits were fasted for at least 12 hours before being given anaesthesia. All rabbits were anaesthetised with an intramuscular injection solution of ketamine hydrochloride $(50 \mathrm{mg} / \mathrm{kg})$ and xylazine hydrochloride $(5 \mathrm{mg} / \mathrm{kg})$. Maintenance amounts (10-15\% of the original dosage) were administered at 45 minute intervals as needed.

\section{Illumination parameters}

Before light application, a Goldmann plano fundus contact lens (OGFA, Ocular Instruments, Inc, Bellevue, WA, USA) was placed on the animal's eye. Laser light (664 nm) was delivered to the fundus transcorneally. Power was verified at the cornea by a power meter (International Light Radiometer Model IL1400A, Detector Head Model SPL024F, Newburyport, MA, USA). A power density of $350 \mathrm{~mW} / \mathrm{cm}^{2}$ was used for all light treatments ( $1200 \mu \mathrm{m}$ spot size). For each rabbit, only one eye was irradiated, while the fellow eye served as a drug only control. Laser irradiation started 10 minutes following injection of either MV6401 or EYP alone. Animals were exposed in four regions to the following photodynamic light dosing schedule (nasal to temporal, inferior to the optic nerve): $3.3 \mathrm{~J} / \mathrm{cm}^{2}$ ( 10 seconds), $5 \mathrm{~J} / \mathrm{cm}^{2}$ (17 seconds), $10 \mathrm{~J} / \mathrm{cm}^{2}$ (34 seconds), and $20 \mathrm{~J} / \mathrm{cm}^{2}(67 \mathrm{sec}-$ onds) which is illustrated in figure 2 . The $3.3 \mathrm{~J} / \mathrm{cm}^{2}$ light dosage was administered in the later laser treatment experiments, but not in the initial dose-response experiments.

\section{Clinical evaluation}

Before the day of PhotoPoint MV6401 photodynamic treatment, all rabbits underwent an initial baseline examination to rule out any pre-existing pathology and to document the baseline condition of the rabbits assigned to the study. Clinical examinations were conducted by slit lamp biomicroscopy or indirect ophthalmoscopy. Baseline fundus and fluorescein angiographic photography was also performed. Following MV6401 injection, any changes in tissue appearance from the baseline examination were documented. Adverse changes that were monitored included but were not limited to exudation, infiltration, opacification, optical distortion, oedema, cell loss, pigmentary disruption, vascular anomaly haemorrhage, atrophy, and dislocation or detachment of the retina.

\section{Photodocumentation}

Fundus photography and fluorescein angiography were performed before photosensitiser injections and after photodynamic light treatments. Angiography was performed with $0.1 \mathrm{ml} / \mathrm{kg}$ body weight of $25 \%$ sodium fluorescein via marginal ear vein injection.

\section{Histology}

Immediately following the last scheduled ophthalmological examination, animals were euthanised by intravenous injection. Both eyes were excised immediately and fixed in phosphate buffered $4 \%$ paraformaldehyde solution (overnight at room temperature) for histological processing. Tissues were embedded in paraffin, cross sectioned for light microscopy, and stained with haematoxylin and eosin. Ophthalmic tissues were evaluated by an investigator (TAC or MHC) masked to the study groups.

\section{Drug and light dosage responses}

In order to establish an appropriate therapeutic MV6401 dosage range, rabbits were divided into six dose-response groups (see table 4), with laser photodynamic treatment sites within the test eye receiving light dosages of 5, 10, and 20 $\mathrm{J} / \mathrm{cm}^{2}$. Subsequently, eyes were evaluated at days 1 and 7 post-treatment, and were excised at day 7 after euthanasia

\begin{tabular}{|c|c|c|c|c|}
\hline $\begin{array}{l}\text { MV6401 dose } \\
(\mu \mathrm{mol} / \mathrm{kg})\end{array}$ & $\begin{array}{l}\text { Days post-treatment } \\
\text { (euthanasia) }\end{array}$ & No* & $\begin{array}{l}\text { Light dose } \\
\left(\mathrm{J} / \mathrm{cm}^{2}\right)\end{array}$ & $\begin{array}{l}\text { Not per drug/light } \\
\text { combination }\end{array}$ \\
\hline 0.075 & $\begin{array}{r}1 \\
7 \\
28 \\
28\end{array}$ & $\begin{array}{l}3 \ddagger \\
3 \ddagger \\
3 \ddagger \\
8\end{array}$ & $\begin{array}{l}20 \\
20 \\
20 \\
20 \\
25\end{array}$ & $\begin{array}{l}3 \\
3 \\
3 \\
4 \\
6\end{array}$ \\
\hline 0.10 & 28 & 2 & 15,20 & 2 \\
\hline $\begin{array}{l}{ }^{*} \text { Number of anim } \\
\text { †Number of eyes } \\
\$ \text { Number of anim } \\
\text { drug only control } \\
\text { TIn this group } 10\end{array}$ & $\begin{array}{l}\text { valuated histologically } \\
\text { of } 16 \text { eyes were treat }\end{array}$ & on & animal wc & ; the fellow eye served o \\
\hline
\end{tabular}




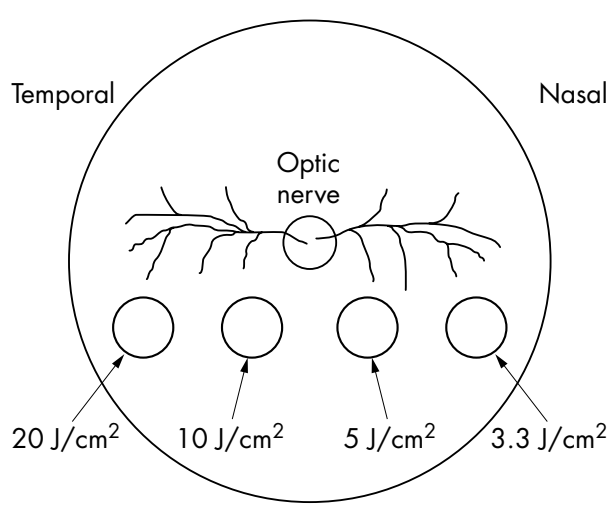

Figure 2 Schematic fundus view of a rabbit's eye which was irradiated with different doses of $664 \mathrm{~nm}$ light using a constant power density of $350 \mathrm{~mW} / \mathrm{cm}^{2}$.

for histopathological analysis. MV6401 dosages ranged from 0.025 to $0.25 \mu \mathrm{mol} / \mathrm{kg}$.

\section{Lesion development following PDT}

In a second set of experiments, the evolving histopathological responses of ocular tissues to MV6401 PDT at different light dosage levels $\left(3.3,5,10\right.$, and $\left.20 \mathrm{~J} / \mathrm{cm}^{2}\right)$ were evaluated, with particular emphasis on the possible post-treatment development of lesions ( see table 5). After the results from the earlier dose-response study suggested that an MV6401 dosage of $0.15 \mu \mathrm{mol} / \mathrm{kg}$ was therapeutically most appropriate, this dose was then used to evaluate possible lesion development at various post-treatment time points up to 28 days.

\section{RESULTS}

\section{Rat corneal neovascularisation model}

A dose-response was observed as MV6401 dosage levels were escalated from $0.01 \mu \mathrm{mol} / \mathrm{kg}$ to $0.1 \mu \mathrm{mol} / \mathrm{kg}$ in Sprague Dawley rats. Fluorescein angiography did not show any closure of the corneal neovasculature at the lowest drug dose $(0.01 \mu \mathrm{mol} / \mathrm{kg})$ when treated at the highest light doses (15$25 \mathrm{~J} / \mathrm{cm}^{2}$ ). The $0.025 \mu \mathrm{mol} / \mathrm{kg}$ dose resulted in an area of neovessel closure the size of the treatment area 1 day following photodynamic treatment, but no effect was evident
Table 4 Rabbit MV6401 dose-response experiments. treatment scheme: MV6401 + $664 \mathrm{~nm}$ laser light (at light dosages of 5,10 , and $20 \mathrm{~J} / \mathrm{cm}^{2}$ )

\begin{tabular}{lll}
\hline Group & No* $^{*}$ & $\begin{array}{l}\text { MV6401 dosage } \\
(\mu \mathrm{mol} / \mathrm{kg})\end{array}$ \\
\hline 1 & 2 & 0.025 \\
2 & 2 & 0.1 \\
3 & 2 & 0.125 \\
4 & 1 & 0.15 \\
5 & 1 & 0.2 \\
6 & 1 & 0.25 \\
\hline *Number of animals. &
\end{tabular}

at 7 days post-treatment. The $0.05 \mu \mathrm{mol} / \mathrm{kg}$ dose demonstrated a light dose dependent response with the most effective drug and light combination at 20 and $25 \mathrm{~J} / \mathrm{cm}^{2}$ showing sustained neovessel closure at 7 days post-treatment. The highest MV6401 doses $(0.075 \mu \mathrm{mol} / \mathrm{kg}$ and $0.10 \mu \mathrm{mol} / \mathrm{kg}$ ) resulted in the largest areas of neovessel closure as well as sustained closure at 7 days (see figs 3 and 4). The optimal dosage scheme was $0.075 \mu \mathrm{mol} / \mathrm{kg}$ MV6401 with a light dosage of $20 \mathrm{~J} / \mathrm{cm}^{2}$, because the neovessel closure at the highest MV6401 and light dose $(0.10 \mu \mathrm{mol} / \mathrm{kg}$ and $20 \mathrm{~J} / \mathrm{cm}^{2}$ ) was accompanied by severe chemosis and loss of selectivity for the neovessels.

The time interval was evaluated for periods from 10 60 minutes between initial drug injection and light dose administration, and the optimal time interval was determined to be 10 minutes based on the maximum closure of the neovasculature (as evidenced by fluorescein angiography).

Effects subsequent to treatment at the highest drug doses $(0.075 \mu \mathrm{mol} / \mathrm{kg}$ and $0.10 \mu \mathrm{mol} / \mathrm{kg})$ were monitored up to 28 days following photodynamic treatment (see fig 3). Corneal fluorescein angiography of the majority of treatment responses showed regrowth or recanalisation of the corneal neovessels by 21 days post-PDT. Histology (fig 4) revealed evidence of neovessel collapse and extensive thrombosis at 1 day post-PDT. Thrombosis was less extensive at 7 days. By 28 days, patent neovessels dominated the treatment field with occasional evidence of thrombosis.

\begin{tabular}{|c|c|c|c|}
\hline Group & $\mathrm{No}^{*}$ & Description & $\begin{array}{l}\text { Days post-treatment } \\
\text { (euthanasia) }\end{array}$ \\
\hline 1 & 3 & $0.15 \mu \mathrm{mol} / \mathrm{kg}$ MV6401 + $664 \mathrm{~nm}$ light & 1 \\
\hline 2 & 3 & $0.15 \mu \mathrm{mol} / \mathrm{kg} \mathrm{MV6401} \mathrm{+} 664 \mathrm{~nm}$ light & 7 \\
\hline 3 & 3 & $0.15 \mu \mathrm{mol} / \mathrm{kg} \mathrm{MV6401} \mathrm{+} 664 \mathrm{~nm}$ light & 14 \\
\hline 4 & 3 & $0.15 \mu \mathrm{mol} / \mathrm{kg} \mathrm{MV} 6401+664 \mathrm{~nm}$ light & 28 \\
\hline 5 & 3 & EYP + $664 \mathrm{~nm}$ light & 1 \\
\hline
\end{tabular}

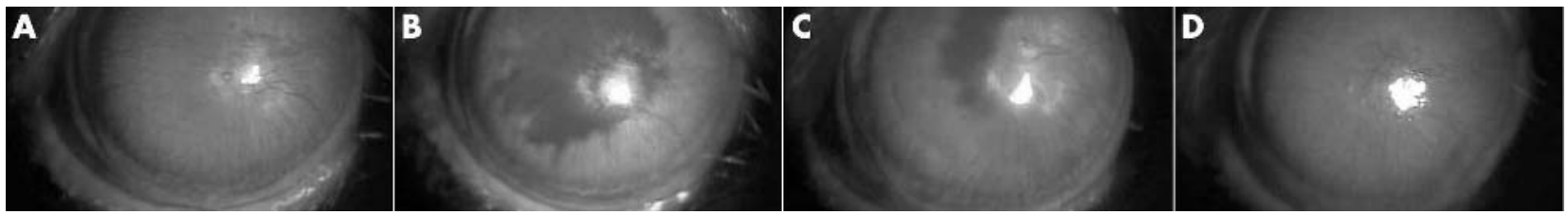

Figure 3 Corneal fluorescein angiograms from a rat treated with $0.075 \mu \mathrm{mol} / \mathrm{kg} \mathrm{MV} 6401$ and $20 \mathrm{~J} / \mathrm{cm}^{2}$ light 10 minutes after drug administration: (A) baseline, (B) 1 day post-PDT, (C) 7 days post-PDT, and (D) 28 days post-PDT. 


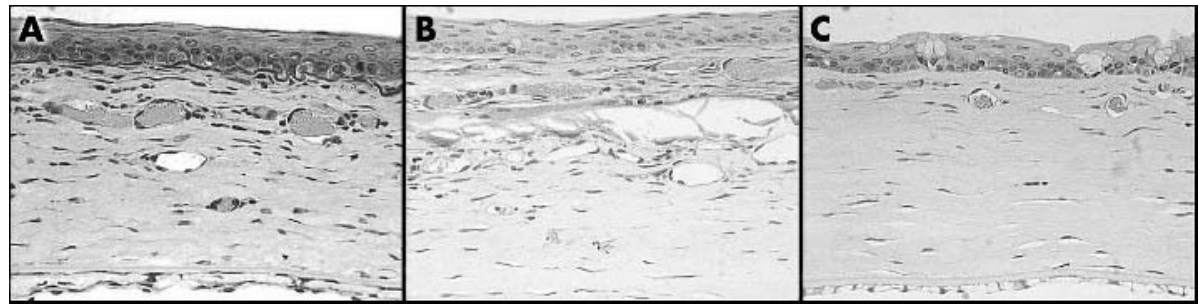

Figure 4 Rat corneal sections

obtained (A) 1 day, (B) 7 days, and (C) 28 days after PDT with $0.075 \mu \mathrm{mol} / \mathrm{kg}$ MV6401 and $20 \mathrm{~J} / \mathrm{cm}^{2}$ light (PIAT interval $=10$ minutes).

\section{Rabbit choriocapillaris dose-response experiments}

The MV6401 dose-response experiments showed no acute fundus lesions, suggesting that laser treatment at the fluences used had no thermal effect, and that the ocular effects observed later were photochemical in origin. At the lowest MV6401 dose $(0.025 \mu \mathrm{mol} / \mathrm{kg})$ there was only minimal retinal pigment epithelium (RPE) mottling, noted variably at 1 day posttreatment, and these findings resolved on examination and angiography by 7 days post-treatment. At MV6401 doses of $0.1 \mu \mathrm{mol} / \mathrm{kg}$ and higher, the lesions exhibited subretinal fluid at post-treatment day 1 , and this finding also resolved by 7 days post-treatment, except at sites where the highest dose was used $(0.25 \mu \mathrm{mol} / \mathrm{kg})$. There were no effects observed on the optic nerve or major retinal vessels outside of the treatment zones. There were no effects observed in the cornea, iris, lens, or vitreous at any of the doses used in this study.
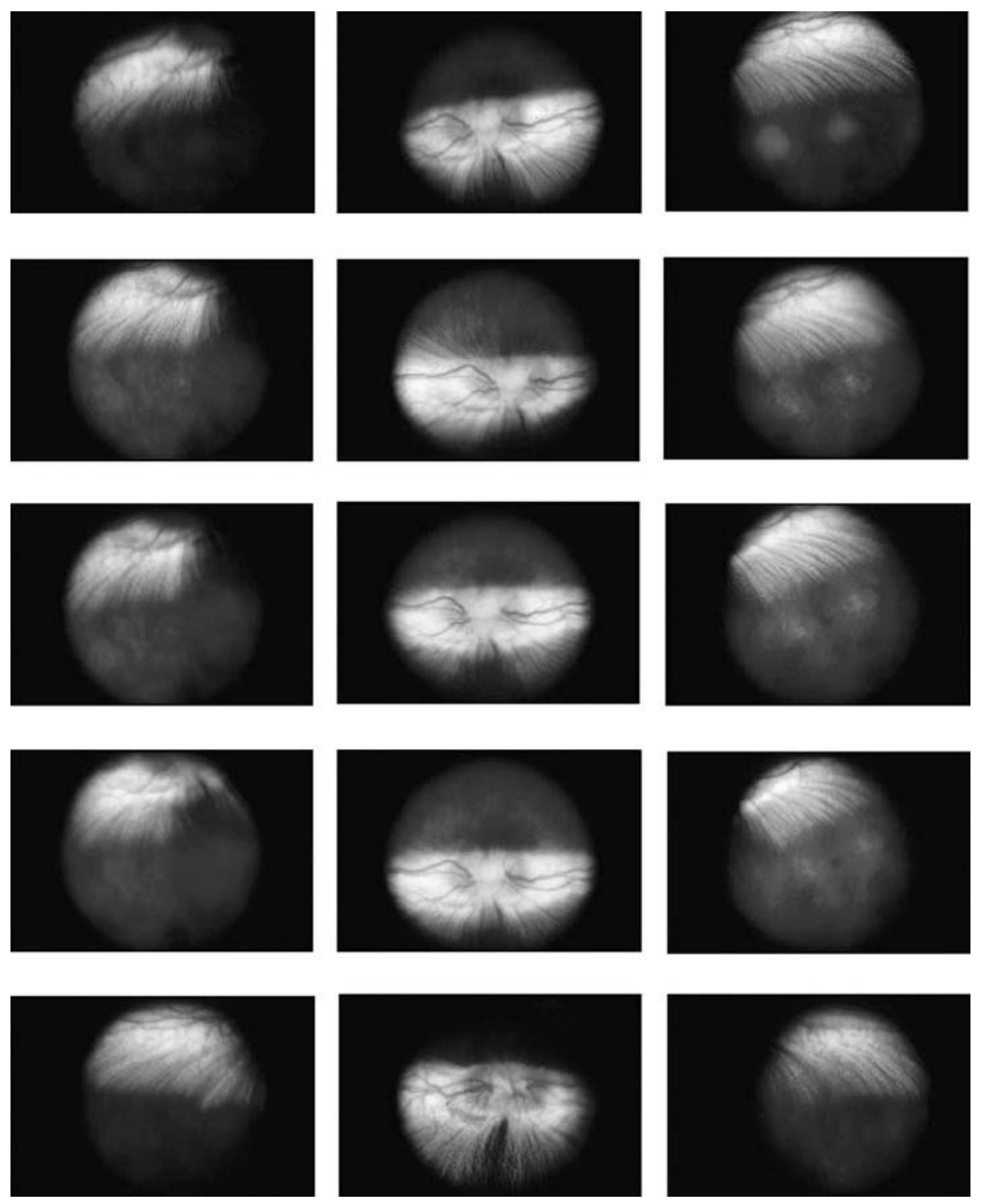

Figure 5 Fundus photographs of laser induced PDT sites (left column: temporal retina containing 20 and $10 \mathrm{~J} / \mathrm{cm}^{2}$ PDT sites, middle column: optic disc, right column: nasal retina containing 5 and $3.3 \mathrm{~J} / \mathrm{cm}^{2}$ PDT sites) at 1 day (top row), 7 days (second row), 14 days (third row), and 28 days (fourth row) post-treatment (MV6401 dosage: $0.15 \mu \mathrm{mol} / \mathrm{kg}$ ). All photographs represent the same eye in one animal. The fifth row illustrates fundus photographs from a control eye (different animal), 1 day following laser light treatment using the same laser parameters described previously. Tissues appeared unaffected here and in later histological sections. 

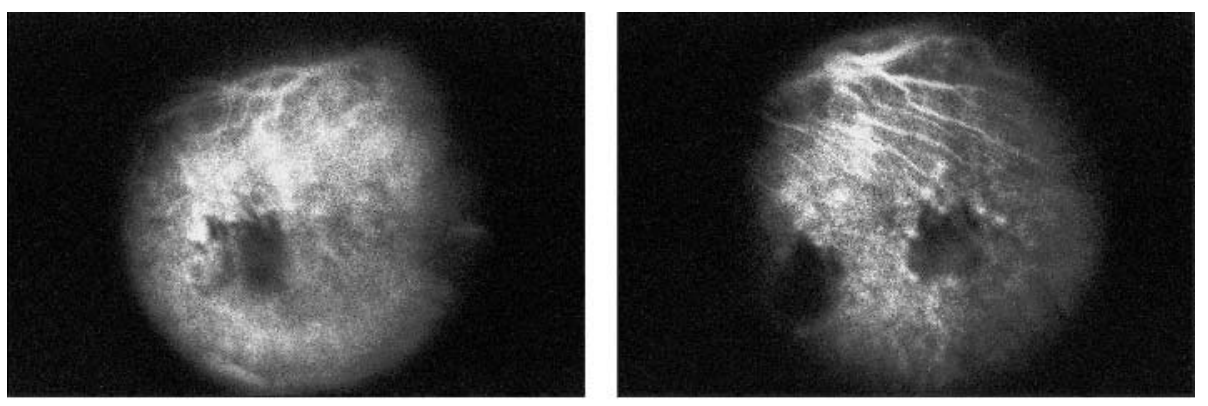

Figure 6 Fluorescein angiography of PDT sites in the (left column) temporal retina $\left(20\right.$ and $10 \mathrm{~J} / \mathrm{cm}^{2}$ sites) and (right column) nasal retina $\left(5 \mathrm{~J} / \mathrm{cm}^{2}\right.$ and $3.3 \mathrm{~J} / \mathrm{cm}^{2}$ sites) at 1 day (top row) and again at 28 days (bottom row) post-treatment. This was the same PDT treated eye as that shown in fundus photographs of figure 5 .
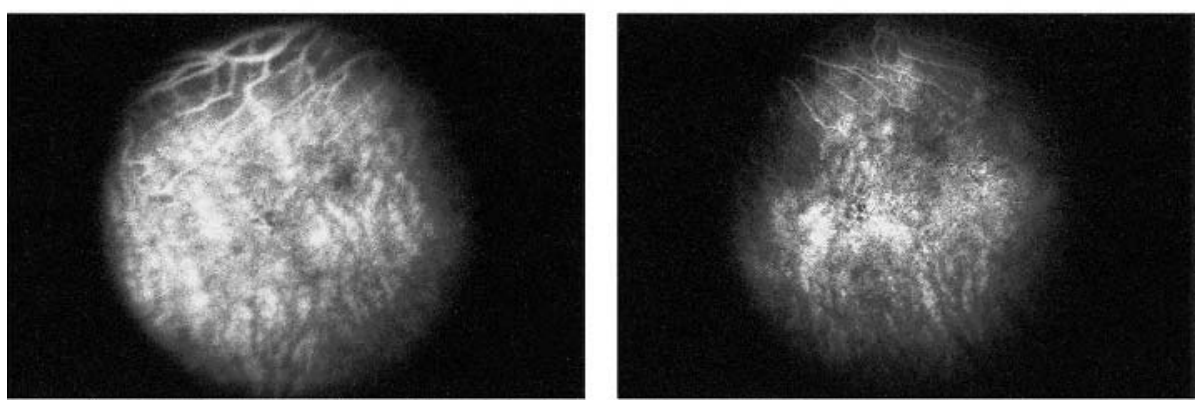

With regard to the desired end point of choriocapillaris closure, there was subthreshold dosing at $0.025,0.1$, and $0.125 \mu \mathrm{mol} / \mathrm{kg} \mathrm{MV6401}$, as fluorescein angiography revealed perfusion of the choroid at 7 days post-treatment. Toxicity was observed on histopathological analysis of photodynamically treated tissues that received 0.20 or $0.25 \mu \mathrm{mol} / \mathrm{kg}$ dosages of MV6401, with RPE atrophy outside of the treatment zones and severe disorganisation of the retinal outer segments.

Photodynamic treatments using an intermediate dosage of MV6401 $(0.15 \mu \mathrm{mol} / \mathrm{kg})$ produced the desired end point, although this result may represent a narrow therapeutic range between 0.125 and $0.20 \mu \mathrm{mol} / \mathrm{kg}$, at least within the rabbit. There were no fundus lesions acutely discernable. At 1 day post-treatment, examination revealed prominent greywhite elevated lesions at each of the three treatment sites, consistent with subretinal fluid. These varied in size and intensity, correlating with the laser light dosage used. Fluorescein angiography showed absolute homogeneous hypofluorescence at each of the lesions, consistent with non-perfusion of the choriocapillaris or with blockage by turbid subretinal fluid/opaque RPE, or both.

By 7 days post-treatment (at the $0.15 \mu \mathrm{mol} / \mathrm{kg}$ dosage), there were three discrete fundus lesions, each consisting of relative (not absolute) RPE atrophy. Compared to posttreatment day 1 , these lesions no longer showed the homogeneous grey-white colour or elevation, suggesting resolution of subretinal fluid. These lesion sites no longer exhibited any adjacent RPE changes outside of the treatment zones. Fluorescein angiography showed homogeneous hypofluorescence at the lesions, suggestive of choriocapillaris nonperfusion. Except for some mild staining at the margins of the lesions there were no other angiographic abnormalities. There were no corneal, iris, lenticular, or vitreous lesions seen at any time point.

At an MV6401 dosage of $0.15 \mu \mathrm{mol} / \mathrm{kg}$, histopathological analysis at 1 week post-treatment demonstrated significant attenuation of the choroidal layer/vasculature, consistent with closure of the choriocapillaris and moderate sized choroidal vessels at each of the photodynamic treatment sites, and this result was consistent with the above mentioned fluorescein angiography findings. There was also attenuation of the photoreceptor layer within the laser treatment sites, which was directly correlated to the laser light dosages. At the highest light dose only $\left(20 \mathrm{~J} / \mathrm{cm}^{2}\right)$ there was subretinal fibrosis.

\section{Rabbit choriocapillaris lesion development with $0.15 \mu \mathrm{mol} / \mathrm{kg} \mathrm{MV6401}$}

Given the findings noted above, further study of the photodynamic response to MV6401 was carried out with

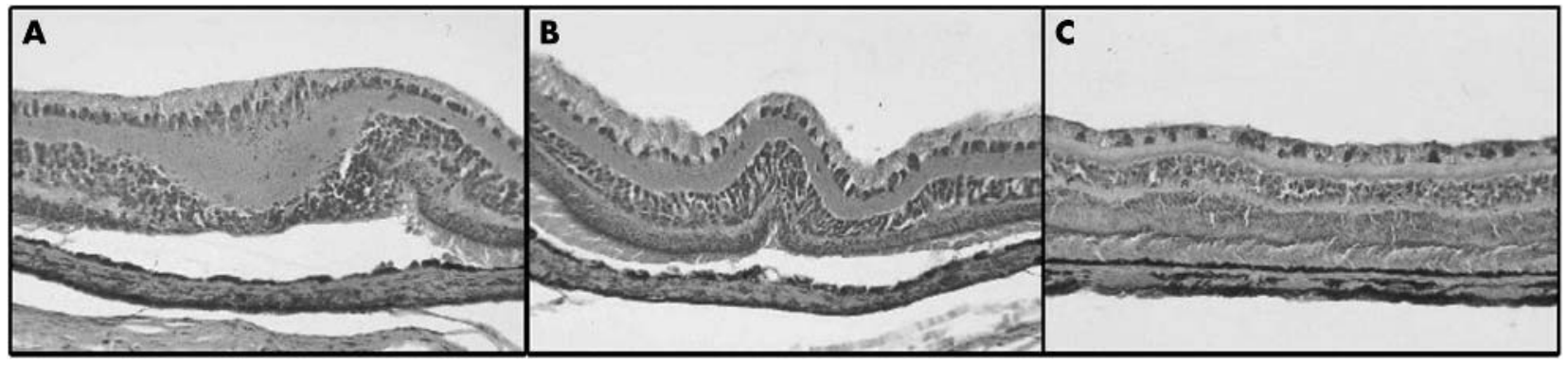

Figure 7 Photomicrographs of retinal/choroidal tissues (radial view) following PDT at duration dependent energy doses of (A) $10 \mathrm{~J} / \mathrm{cm}^{2}$ and (B) $5 \mathrm{~J} / \mathrm{cm}^{2}$ that showed closure of choroidal vessels and attenuation $\left(5 \mathrm{~J} / \mathrm{cm}^{2}\right)$ and partial ablation $\left(10 \mathrm{~J} / \mathrm{cm}^{2}\right)$ of photoreceptors. In each case, MV6401 dosage was $0.15 \mu \mathrm{mol} / \mathrm{kg}$. Control tissues (C), representing a laser site at the $5 \mathrm{~J} / \mathrm{cm}^{2}$ light dosage level, received laser light treatment without MV6401 infusion. Here retinal structures remained completely intact and choroidal vessels remain open. 
the $0.15 \mu \mathrm{mol} / \mathrm{kg}$ MV6401 dosage and included an additional lower laser light dosage of $3.3 \mathrm{~J} / \mathrm{cm}^{2}$.

All treatment lesions (fig 5) showed the presence of subretinal fluid at day 1 post-treatment, although this finding resolved by day 7 (except at the highest light dose $\left(20 \mathrm{~J} / \mathrm{cm}^{2}\right)$ in which fluid was variably present, but resolved by 14 days post-treatment). The subretinal exudate variably evolved to subretinal fibrosis within the higher light dosage sites $\left(10\right.$ and $\left.20 \mathrm{~J} / \mathrm{cm}^{2}\right)$ and this effect appeared most prominently in rabbits which demonstrated relative RPE hypertrophy at baseline. It is possible that the more prominent RPE mounts a more aggressive metaplastic/ fibroblastic response to photochemical injury. In general, examination showed that the remaining (lower light dosage) lesion sites evolved to RPE mottling without subretinal exudate or fibrosis at the later time points.

With regard to photodynamic closure of the choroidal vessels, fluorescein angiography (fig 6) revealed homogeneous hypofluorescence at the lesions, suggestive of choriocapillaris non-perfusion, at day 7 post-treatment. This effect further evolved to only mottled hypofluorescence with marginal staining by 28 days. One interpretation of this change would be the possible reperfusion of the choroidal vessels. However, histopathological analysis (fig 7) showed significant attenuation of the choroidal layer/vasculature, suggestive of primary closure of the choriocapillaris and of moderate sized choroidal vessels. There was also attenuation of the photoreceptor layer following treatment at the 3.3 and $5.0 \mathrm{~J} / \mathrm{cm}^{2}$ laser light dosages with improvement noted by 28 days. At the higher ( 10 and $20 \mathrm{~J} / \mathrm{cm}^{2}$ ) laser light dosages, generalised damage to the photoreceptors was observed. Control eyes, receiving laser light treatments without infusion of MV6401, did not exhibit any vessel closure or damage to the retina.

\section{DISCUSSION}

This study evaluated the new photosensitiser PhotoPoint MV6401, indium chloride methyl pyropheophorbide. As noted previously, pyropheophorbide based photodynamic therapy has been well studied for utilisation in cancer applications. ${ }^{1-3}$ These compounds are well described chemically, are hydrophobic, absorb light above $600 \mathrm{~nm}$ for enhanced tissue penetration, have excellent photosensitising efficiency, and may not cause prolonged skin photosensitivity experienced with porphyrin derivatives, such as verteporfin. ${ }^{1-3}$ Verteporfin, an efficient generator of singlet oxygen, shows peak absorption in the ultraviolet A range, as well as a secondary absorption peak between 680 and $695 \mathrm{~nm}$; in ophthalmic applications, it is activated by low power, non-thermal laser light at $689 \mathrm{~nm}$, which is thought to penetrate blood, melanin, and fibrous tissue. ${ }^{11-13}$ Like verteporfin, MV6401 possesses two main absorption peaks in the ultraviolet and red ranges, at $423 \mathrm{~nm}$ (molar extinction coefficient $101000 \mathrm{M}^{-1} \mathrm{~cm}^{-1}$ ) and $659 \mathrm{~nm}$ (74000 $\mathrm{M}^{-1} \mathrm{~cm}^{-1}$ ).

The current study, which demonstrates efficacy and selectivity in experimental ocular models of rat corneal neovascularisation closure and of rabbit choriocapillaris closure, suggests that PhotoPoint MV6401 could potentially be used as a photosensitiser in ophthalmic applications. In the rat corneal neovascularisation model, effective closure of these vessels was achieved with an MV6401 dosage of $0.075 \mu \mathrm{mol} / \mathrm{kg}$ and a laser light dosage of $20 \mathrm{~J} / \mathrm{cm}^{2}$. In the rabbit choriocapillaris closure experiments, a $0.15 \mu \mathrm{mol} / \mathrm{kg}$ dosage produced the most desirable end point with preferential effect on the choriocapillaris and choroid and minimal retinal toxicity. Specifically, angiography and histology demonstrated primary closure of the choriocapillaris and moderate sized choroidal vessels. However, limitations of this study include that lack of power to make definitive claims about dosing and the limited ability to model human choriocapillaris and choriodal neovascularisation with the rat and rabbit model; further study with this agent in a primate model has recently been completed.

\section{Authors' affiliations}

T A Ciulla, M H Criswell, Retina Service Research Laboratories, Department of Ophthalmology, Indiana University School of Medicine, Indianapolis, IN, USA

W J Snyder, W Small IV, Miravant Medical Technologies Inc., Santa Barbara, CA, USA

Supported by National Eye Institute Grant R44 EY1 1191, Business Innovation Research Program via Miravant Medical Technologies, by a grant from Miravant Medical Technologies Inc, and by an unrestricted grant from Research to Prevent Blindness, Inc, New York. TA Ciulla is a recipient of a Career Development Award from Research to Prevent Blindness, Inc, New York, USA.

Proprietary interest: Drs Snyder and Small are employees of Miravant Medical Technologies Inc.

This research investigation was performed at both locations.

PhotoPoint is a trademark of Miravant Medical Technologies, Santa Barbara, CA, USA.

\section{REFERENCES}

1 Payne JT, McCaw DL, Casteel SW, et al. Pharmacokinetics of pyropheophorbide-a-hexyl ether in the dog. Lasers Surg Med 1996;18:406-9.

2 Bellnier DA, Henderson BW, Pandey RK, et al. Murine pharmacokinetics and antitumor efficacy of the photodynamic sensitizer 2-[1-hexyloxyethyl]-2devinyl pyropheophorbide-a. J Photochem Photobiol B 1993;20:55-61.

3 Pandey RK, Sumlin AB, Constantine S, et al. Alkyl ether analogs of chlorophyll-a derivatives: Part 1. Synthesis, photophysical properties and photodynamic efficacy. Photochem Photobiol 1996;64:194-204.

4 Primbs GB, Casey R, Wamser K, et al. Photodynamic therapy for corneal neovascularization. Ophthalmic Surg Lasers 1998;29:832-8.

5 Gohto Y, Obana A, Kaneda K, et al. Photodynamic effect of a new photosensitizer ATX-S10 on corneal neovascularization. Exp Eye Res 1998;67:313-22.

6 Moshfeghi DM, Peyman GA, Moshfeghi AA, et al. Ocular vascular thrombosis following tin ethyl etiopurpurin (SnET2) photodynamic therapy: time dependencies. Ophthalmic Surg Lasers 1998;29:663-8.

7 Peyman GA, Moshfeghi DM, Moshfeghi A, et al. Photodynamic therapy for choriocapillaris using tin ethyl etiopurpurin (SnET2). Ophthalmic Surg Lasers 1997;28:409-17.

8 Costa RA, Farah ME, Freymuller E, et al. Choriocapillaris photodynamic therapy using indocyanine green. Am J Ophthalmol 2001;132:557-65.

9 Huang A, Watson B, Hernandez $E$, et al. Induction of conjunctival transdifferentiation on vascularized corneas by photothrombotic occlusion of corneal neovascularization. Ophthalmology 1988;95:228-35.

10 Tseng S, Hirst L, Farazdaghi M, et al. Goblet cell density and vascularization during conjunctival transdifferentiation. Invest Ophthalmol Vis Sci 1984;25:1168-76.

11 Bressler NM. Verteporfin therapy of subfoveal choroidal neovascularization in age-related macular degeneration: two-year results of a randomized clinical trial including lesions with occult with no classic choroidal neovascularizationverteporfin in photodynamic therapy report 2. Am J Ophthalmol 2002; 133: 168-9

12 Blumenkranz MS, Bressler NM, Bressler SB, et al. Verteporfin therapy for subfoveal choroidal neovascularization in age-related macular degeneration: three-year results of an open-label extension of 2 randomized clinical trialsTAP Report no 5. Arch Ophthalmol 2002;120:1307-14.

13 Anon. Guidelines for using verteporfin (Visudyne) in photodynamic therapy to treat choroidal neovascularization due to age-related macular degeneration and other causes. Retina 2002;22:6-18. 